\title{
25 Research Square \\ Early Ascorbic Acid Administration Prevents Vascular Endothelial Cell Damage in Septic Mice
}

\section{Yutaro Madokoro ( $\square$ mado0705@m.kufm.kagoshima-u.ac.jp )}

Kagoshima University Faculty of Medicine: Kagoshima Daigaku Igakubu https://orcid.org/0000-00031706-6076

\section{Chinatsu Kamikokuryo}

Kagoshima University Graduate School of Medical and Dental Sciences

\section{Shuhei Niiyama}

Kagoshima University Graduate School of Medical and Dental Sciences

\section{Takashi Ito}

Kumamoto University

\section{Satoshi Hara}

Tokyo Institute of Technology

Hiroshi Ichinose

Tokyo Institute of Technology

\section{Yasuyuki Kakihana}

Kagoshima University Graduate School of Medical and Dental Sciences

\section{Research}

Keywords: ascorbic acid, sepsis, tetrahydrobiopterin, endothelial dysfunction, syndecan

Posted Date: September 30th, 2021

DOl: https://doi.org/10.21203/rs.3.rs-923967/v1

License: (c) (i) This work is licensed under a Creative Commons Attribution 4.0 International License. Read Full License 


\section{Abstract}

Background: Ascorbic acid (AsA) therapy for sepsis is thought to have a protective effect on vascular endothelial cells. However, the effect of AsA therapy on endothelial cell dysfunction over time and the appropriate timing for AsA administration to demonstrate efficacy is unclear.

Methods: Septic mice were induced by cecal ligation and puncture (CLP). The effect of AsA administration $(200 \mathrm{mg} / \mathrm{kg}$ ) on vascular endothelial cell dysfunction in sepsis was examined using septic mice at two administration timings: early group (AsA was administered immediately after CLP) and late group (AsA was administered $12 \mathrm{~h}$ after CLP). First, survival rates were compared between the early and late administration groups. Next, the dihydrobiopterin/tetrahydrobiopterin $\left(\mathrm{BH}_{2} / \mathrm{BH}_{4}\right)$ ratio, serum syndecan-1, and endothelial nitric oxide synthase (eNOS) were measured as indicators of vascular endothelial cell damage, and liver tissue was examined for organ damage to verify the effect of early AsA administration in septic mice.

Results: In survival experiments, the early group showed significantly improved survival compared to the non-treatment group $(p<0.05)$, while the late group showed no improved survival compared to the nontreatment group. The $\mathrm{BH}_{2} / \mathrm{BH}_{4}$ ratio increased after 6 hours following CLP, and the increase was suppressed by early AsA administration ( $0.12 \pm 0.02$ vs. $0.07 \pm 0.016, p<0.05)$. Serum syndecan- 1 levels were significantly elevated at $12 \mathrm{~h}$ after CLP, and early AsA administration prevented the increase (25.4 \pm 12.1 vs. $9.9 \pm 2.7 \mathrm{mg} / \mathrm{ml}, \mathrm{p}<0.05$ ). The expression of eNOS at $12 \mathrm{~h}$ after CLP was decreased in the nontreatment group, but the expression was protected by early AsA administration. Moreover, hematoxylin and eosin staining of hepatocytes showed reduced liver damage in the early group compared to the nontreatment group.

Conclusions: In septic mice, early AsA administration immediately after CLP may have protective effects on vascular endothelial cells by decreasing the $\mathrm{BH}_{2} / \mathrm{BH}_{4}$ ratio, resulting in reduced organ dysfunction and improved survival. To achieve this effect, early administration of $\mathrm{AsA}$ is required before $\mathrm{BH}_{4}$ is oxidized.

\section{Background}

Sepsis is a life-threatening organ dysfunction caused by a dysregulated host response to infection [1]. The World Health Organization reports that although sepsis mortality rates have declined in recent decades, it still causes 11 million deaths annually [2]. Currently, there is no definitive treatment for sepsis, and the recommended treatment includes early detection, early antibiotic administration, appropriate infusion therapy, and optimal timing of vasopressor administration; however, the mortality rate still remains high [3].

Sepsis progresses to septic shock, which is caused by increased vascular permeability due to endothelial dysfunction and vasodilatory hypotension caused by elevated levels of nitric oxide (NO), resulting in multiple organ failure and significantly reduced survival $[4,5]$. One of the causes of vascular endothelial 
dysfunction is reactive oxygen species produced by the uncoupling of endothelial nitric oxide synthase (eNOS) [6]. eNOS is an important molecule that regulates vascular homeostasis by generating NO, with tetrahydrobiopterin $\left(\mathrm{BH}_{4}\right)$ as a cofactor. $\mathrm{BH}_{4}$ is produced from guanosine triphosphate and acts as an essential cofactor for various enzymes. $\mathrm{BH}_{4}$ is easily oxidized to dihydrobiopterin $\left(\mathrm{BH}_{2}\right)$, and the binding affinities of $\mathrm{BH}_{4}$ and $\mathrm{BH}_{2}$ to eNOS are equal. $\mathrm{NO}$ is produced when $\mathrm{BH}_{4}$ binds to eNOS, whereas superoxide is produced when $\mathrm{BH}_{2}$ binds to eNOS [7]. The reaction that produces superoxide is referred to as "uncoupling" of nitric oxide synthase. When availability of $\mathrm{BH}_{4}$ is limited, the $\mathrm{BH}_{2} / \mathrm{BH}_{4}$ ratio, rather than the absolute amounts of $\mathrm{BH}_{4}$ and $\mathrm{BH}_{2}$, is associated with vascular endothelial function [8-10]. Endothelial dysfunction decreases the permeability barrier function, increases glycocalyx shedding and leukocyte adhesion, and initiates a pro-coagulant and anti-fibrinolytic state [5]. In particular, glycocalyx shedding plays a major role in exacerbating sepsis. One of the core proteins that constitute the glycocalyx is syndecan-1, which is released from the vascular endothelium into the bloodstream when vascular endothelial cells are damaged; therefore, serum syndecan-1 levels are used as a marker of glycocalyx damage [11].

Ascorbic acid (AsA), also known as vitamin C, is an important antioxidant that prevents the oxidation of various substances, including $\mathrm{BH}_{4}$. Vitamin $\mathrm{C}$ levels are decreased in critically ill patients, such as those with sepsis [12]. In sepsis, AsA administration has been reported to improve survival and protect microvascular functions [13]. However, the optimal timing for AsA administration to protect endothelial cells remains unclear. In this study, we administered AsA at the early and late phases and evaluated the effect of AsA on endothelial cells in a mouse model of sepsis.

\section{Methods}

\section{Animals}

Adult C57BL/ 6 mice (9-11-week-old males) weighing $25 \mathrm{~g}$ were obtained from Kyudo (Fukuoka, Japan), housed under standard environmental conditions, and maintained at $23 \pm 1^{\circ} \mathrm{C}$ with a 12 -h light/dark cycle. All animal experiments were conducted under the rules approved by the Institutional Animal Care and Use Committee of Kagoshima University.

\section{Cecal Ligation and Puncture (CLP)}

The cecal ligation and puncture (CLP) model is the gold standard for experimental models of sepsis. Septic shock was induced by CLP, as previously described, with slight modifications [14]. Briefly, mice were anesthetized with isoflurane, and the mouse cecum was ligated with a 3 - 0 silk suture and punctured in one place with a 21-gauge needle. The cecum was retracted into the abdominal cavity, and the incision was sutured with $3-0$ nylon. For sham-operated mice, only open and closed abdominal procedures were performed without CLP. At different times during each experiment, blood, liver, and heart tissues were collected and analyzed under inhalation anesthesia. At 6, 12, and $24 \mathrm{~h}$ after CLP and sham operation, the blood of mice was collected by inferior vena cava puncture, after which the animals were 
sacrificed. Blood samples were centrifuged at $2000 \mathrm{~g}$ for $10 \mathrm{~min}$ to collect plasma and stored at $-80^{\circ} \mathrm{C}$ until analysis. At $12 \mathrm{~h}$ after CLP and sham operation, the myocardial tissue samples were analyzed for eNOS expression, and liver tissue samples were examined for pathological changes. After the operation, buprenorphine $(0.05 \mathrm{mg} / \mathrm{kg})$ was repeatedly administered every $12 \mathrm{~h}$ by subcutaneous injection.

\section{Experimental design}

\section{Survival experiment: CLP vs CLP + AsA (Early)}

Mice received $40 \mathrm{ml} / \mathrm{kg}$ of normal saline or AsA (200 mg/kg) by subcutaneous injection immediately after the operation. Mice were randomized into the following groups: 1) sham, 2) sham + AsA, 3) CLP, and 4) $C L P+$ AsA groups. The mice were monitored for $72 \mathrm{~h}$.

\section{Survival experiment: CLP vs CLP + AsA (Late)}

Mice received $40 \mathrm{ml} / \mathrm{kg}$ of normal saline by subcutaneous injection immediately after the operation, and $10 \mathrm{ml} / \mathrm{kg}$ of normal saline or AsA (200 mg/kg) by subcutaneous injection at $12 \mathrm{~h}$ after the operation. Mice were randomized into the following groups: 1) sham, 2) CLP, and 3) CLP + AsA (late). The mice were monitored for $72 \mathrm{~h}$.

\section{Measurement of $\mathrm{BH}_{4}$ and $\mathrm{BH}_{2}$ and calculation of $\mathrm{BH}_{2} / \mathrm{BH}_{4}$}

$\mathrm{BH}_{4}$ is a substance that oxidizes easily, and oxidation was prevented by adding $0.2 \%$ dithioerythritol (a final concentration). $\mathrm{BH} 4$ and $\mathrm{BH} 2$ were measured separately by the post-column oxidation method using high-performance liquid chromatography with a fluorescence detector [15]. The plasma samples $(100 \mu \mathrm{L})$ were deproteinized by adding $25 \mu \mathrm{L}$ of $1 \mathrm{M}$ perchloric acid containing $0.5 \mathrm{mM}$ EDTA, followed by centrifugation. The supernatants were filtered through a $0.2 \mu \mathrm{m}$ filter. $\mathrm{The}^{\mathrm{B}} \mathrm{H}_{2} / \mathrm{BH}_{4}$ ratio was calculated by dividing $\mathrm{BH}_{2}$ by $\mathrm{BH}_{4}$.

\section{Measurement of Syndecan-1}

Plasma syndecan-1 levels were measured using a Murine CD138 ELISA Kit (Diaclone, France).

\section{Western blotting analysis}

The heart was homogenized in a buffer (T-PER Tissue Protein Extraction Reagent; Thermo scientific, Rockford, USA). The proteins were separated using 10\% SDS-PAGE. The proteins were transferred onto nitrocellulose membranes. The blots were probed with specific primary antibodies against mouse eNOS and glyceraldehyde 3-phosphate dehydrogenase. Immunoreactive bands were visualized using an enhanced chemiluminescence system.

\section{Histologic Examination}

Liver tissue specimens were fixed in $10 \%$ formalin and embedded in paraffin. They were stained with hematoxylin and eosin to evaluate the degree of injury. 


\section{Statistics analysis}

Survival rates were analyzed using the Kaplan-Meier method. Survival times were compared using the log-rank test. Data are expressed as mean \pm standard error. The Kruskal-Wallis test was used to detect differences between the groups. Significant differences were considered if $P$ value was $<0.05$.

\section{Results}

\section{Early administration of AsA improves survival rate of mice with CLP-induced sepsis compared to late administration of AsA.}

We compared the survival rates after operation between Sham, Sham + AsA, CLP, and CLP + AsA (Early) (Fig. 1A). None of the CLP mice used in this study survived to $45 \mathrm{~h}$ after the operation. All Sham $+\mathrm{NS}$ and Sham + AsA mice survived for $72 \mathrm{~h}$. In the CLP + AsA (Early) mice group, 3 of 10 mice survived after operation (30\%).

The CLP + AsA (Early) mice group showed significantly higher survival rates than the CLP mice group.

Second, we compared the survival rates after operation among sham, CLP, and CLP + AsA groups (late) (Fig. 1B). All sham mice survived for $72 \mathrm{~h}$. In the CLP and CLP + AsA (late) mice groups, 1 of 10 mice survived after operation (10\%). The CLP + AsA (Late) mice group showed no difference in survival rates compared to the CLP mice group.

$\mathrm{BH}_{2} / \mathrm{BH}_{4}$ ratio increased 6 hours after the operation and continued to increase over time. Early administration of AsA prevented an increase of $\mathrm{BH}_{2} / \mathrm{BH}_{4}$ ratio.

To elucidate the dynamics of $\mathrm{BH}_{4}$ and $\mathrm{BH}_{2}$ in CLP-induced sepsis and how the dynamics of pteridine change with the administration of $\mathrm{AsA}$, we measured $\mathrm{BH}_{4}$ and $\mathrm{BH}_{2}$ and then calculated $\mathrm{BH}_{2} / \mathrm{BH}_{4}$. Serum $\mathrm{BH}_{4}$ and $\mathrm{BH}_{2}$ levels were determined in CLP and sham mice at 6,12 , and $24 \mathrm{~h}$ after the operation.

Both $\mathrm{BH}_{4}$ and $\mathrm{BH}_{2}$ showed a significant increase $24 \mathrm{~h}$ after the operation (Fig. 2). The ratio of $\mathrm{BH}_{2}$ to $\mathrm{BH}_{4}$ was significantly elevated in the CLP group compared to the early AsA group starting at $12 \mathrm{~h}$.

Syndecan-1 levels increased after $12 \mathrm{~h}$, but early administration of AsA suppressed this increase. The expression of eNOS in myocardial tissues was also maintained by the early administration of AsA.

Syndecan-1 level and eNOS expression in myocardial tissues were measured to evaluate whether early administration of AsA protects vascular endothelial cells.

Syndecan-1 at $12 \mathrm{~h}$ was significantly higher in the AsA-non-treated group than in the AsA-treated group (Fig. 3). The expression of eNOS was measured to evaluate vascular endothelial cells and was assessed in myocardial tissue $12 \mathrm{~h}$ after operation. Two samples from each of the normal, CLP, and CLP + AsA groups were collected and evaluated by western blotting. eNOS expression was lower in the CLP group 
than in the normal group. Compared to the AsA non-treated group, the early AsA group maintained eNOS expression. eNOS expression was maintained by AsA administration.

\section{Liver organ damage was reduced by early AsA administration}

Finally, liver tissue was stained with hematoxylin and eosin and observed under a microscope to evaluate organ damage due to sepsis. Each sample was collected $12 \mathrm{~h}$ after the operation.

No histological differences were observed between the control and sham mice. In CLP mice, the arrangement of hepatocytes was markedly disorganized (Fig. 4). In contrast, hepatocyte disarrangement was reduced in CLP + AsA (Early) mice, although not as orderly as in the control and sham mice.

\section{Discussion}

In this study, we showed that early AsA administration compared to late AsA administration may improve the survival rate of a mouse model of sepsis by reducing vascular endothelial cell damage. Despite reports that administration of AsA to septic mice improves prognosis, there are no reports of differences in prognosis depending on the timing of administration $[13,16]$. Here, we discuss the mechanism underlying the effectiveness of early AsA administration in reducing vascular endothelial cell damage and the appropriate timing of AsA administration.

The severity of illness and death in septic patients is related to organ damage caused by microcirculatory disturbances and increased vascular permeability due to vascular endothelial dysfunction [4]. The $\mathrm{BH}_{2} / \mathrm{BH}_{4}$ ratio correlates with vascular endothelial function $[8,17]$. Although AsA has antioxidant properties and inhibits $\mathrm{BH}_{4}$ oxidation, it is ineffective in reducing the already oxidized $\mathrm{BH}_{2}$. In animal experiments using guinea pigs, increased $\mathrm{BH}_{2} / \mathrm{BH}_{4}$ ratio has been shown in AsA-deficient models. AsA levels in the body are decreased in critically ill patients, who often experience difficulties in taking AsA orally, and, therefore, require supplemental therapy [13]. In our septic mice, we also confirmed a decrease in AsA plasma concentration in preliminary experiments (data not shown). In this septic mouse, the $\mathrm{BH}_{2} / \mathrm{BH}_{4}$ ratio increased, suggesting that the lack of AsA could not inhibit $\mathrm{BH}_{4}$ oxidation. In case of absolute or relative lack of $\mathrm{BH}_{4}$, eNOS undergoes an uncoupling reaction, which produces superoxide, instead of $\mathrm{NO}$, that reacts to form peroxynitrite $\left(\mathrm{ONOO}^{-}\right)$, a powerful oxidant $[7,18,19]$. Our study showed that the $\mathrm{BH}_{2} / \mathrm{BH}_{4}$ ratio increased at $6 \mathrm{~h}$ after CLP. Early AsA administration immediately after operation significantly suppressed $\mathrm{BH}_{2} / \mathrm{BH}_{4}$ ratio increase. AsA administration has been reported to inhibit $\mathrm{BH}_{4}$ oxidation [20]. Although the optimal AsA dose is unknown, the antioxidant capacity of vitamin $\mathrm{C}$ is dosedependent, and a plasma vitamin C concentration of $175 \mathrm{mg} / \mathrm{l}(1000 \mu \mathrm{mol} / \mathrm{I})$ or higher is required to demonstrate radical scavenging capacity. Vitamin $\mathrm{C}(10 \mathrm{~g})$ is required to achieve a plasma concentration of more than $1000 \mu \mathrm{mol} / \mathrm{I}$ [21]. In humans, the AsA dosage for sepsis is $200 \mathrm{mg} / \mathrm{kg} /$ day in most cases, but a very high volume of AsA ( $66 \mathrm{mg} / \mathrm{kg} / \mathrm{hour}$ ) was shown to be effective in the very early stage of burn 
injury [22]. In addition, another study reported that vitamin C therapy at doses as high as $10 \mathrm{~g}$ within 2 days of admission reduced mortality in patients with severe burns [23], and no major side effects were observed, even with such a very high dose. Therefore, the optimal dosage of AsA should be investigated. Thus, although the effective dosage of vitamin $\mathrm{C}$ for critically ill patients varies according to the disease state, $200 \mathrm{mg} / \mathrm{kg} /$ day of AsA was considered the optimal dosage for this experiment as its effectiveness has been demonstrated previously in septic mice [14, 18, 24, 25]. As a result, early AsA administration may improve $\mathrm{ONOO}^{-}$generation, suggesting a protective effect on endothelial cells. In the late AsA administration group, increased serum syndecan-1 levels, an indicator of endothelial cell damage, and decreased eNOS expression, an indicator of endothelial cell protection, were observed $12 \mathrm{~h}$ after the operation. By contrast, in the early AsA administration group, both serum syndecan-1 levels and eNOS expression showed protective effect on the vascular endothelium. Increased serum syndecan-1 levels in sepsis are associated with vascular permeability and organ damage [26]. Serum syndecan-1 levels are likely to be useful in diagnosing sepsis and may be related to its severity [27]. In our single-center study, syndecan-1 was a predictor of fatal outcome in septic patients [28]. Moreover, we examined liver tissues for organ damage. Indeed, organ damage occurred after $12 \mathrm{~h}$ in the group with elevated syndecan-1, but it was reduced in the group with suppressed syndecan-1 following early AsA administration. The difference in survival may be due to the protection of vascular endothelial cells by early AsA administration, thus suppressing organ damage.

In recent years, the effects of AsA administration in patients with septic shock have received much attention $[29,30]$. The administration of AsA alone, as well as the simultaneous administration of vitamin B1 and hydrocortisone, have been studied widely. In particular, the simultaneous administration of vitamin B1 and hydrocortisone is known as HAT therapy [31-34]. Given that several recent studies have shown no positive effect of AsA administration in septic shock patients, it remains controversial whether AsA should be administered to these patients [35-37]. Some studies have cited delayed administration as a limiting factor to obtaining a good effect of AsA in septic shock [36]. In our septic mouse, an increase in the $\mathrm{BH}_{2} / \mathrm{BH}_{4}$ ratio, which causes $\mathrm{ONOO}^{-}$, had already occurred after $6 \mathrm{~h}$. In addition, organ damage and vascular endothelial cell damage also occurred; thus, administration of AsA at this time would not have been effective. Therefore, in studies reporting no effect of AsA therapy, it is possible that AsA was administered after the $\mathrm{BH}_{2} / \mathrm{BH}_{4}$ ratio had already increased, as we have shown in this study. Early high-dose AsA administration is effective in patients with sepsis [38], including those with hypoalbuminemia or severe organ failure [39]. In this study, we only mentioned the protective effect of AsA on vascular endothelial cells by suppressing the increase in $\mathrm{BH}_{2} / \mathrm{BH}_{4}$ ratio, but AsA has additional effects, such as catecholamine production [40], adrenocorticotropic hormone production [41], and direct scavenging of free radicals [42], which may improve the prognosis of sepsis through various pathways [43].

This study has several limitations. First, it is unclear whether the results of this mouse sepsis model would be similar to those of human sepsis. Changes in $\mathrm{BH}_{4}$ and $\mathrm{BH}_{2}$ over time may differ between humans and mice. Second, because mice can synthesize AsA in their bodies, the dynamics of AsA 
concentration in their bodies may be different from those of humans. The appropriate dosage needs to be discussed in both human and animal studies. However, our present findings indicate that the timing of AsA administration affects prognosis and that the $\mathrm{BH}_{2} / \mathrm{BH}_{4}$ ratio is related to the mechanism of septic shock.

\section{Conclusion}

In the CLP mouse model, an increase in the $\mathrm{BH}_{2} / \mathrm{BH}_{4}$ ratio, which causes vascular endothelial cell damage, occurred $6 \mathrm{~h}$ after the disease onset. In the present study, administration of AsA at an earlier time before the increase in the $\mathrm{BH}_{2} / \mathrm{BH}_{4}$ ratio improved the prognosis of the CLP mouse model by protecting the vascular endothelium. In the future, it will be necessary to evaluate the time course of the $\mathrm{BH}_{2} / \mathrm{BH}_{4}$ ratio and the post-onset dynamics of syndecan- 1 in humans, as well as study the appropriate timing for AsA administration.

\section{Abbreviations}

AsA

Ascorbic acid

NO

nitric oxide

eNOS

endothelial NO synthase

$\mathrm{BH}_{4}$

tetrahydrobiopterin

$\mathrm{BH}_{2}$

dihydrobiopterin

CLP

cecal ligation and puncture

$\mathrm{ONOO}^{-}$

peroxynitrite

\section{Declarations}

\section{Ethical approval and consent to participate}

All animal experiments were conducted under the rules approved by the Institutional Animal Care and Use Committee of Kagoshima University (approval number MD18126). Consent to Participate is 'Not applicable'.

\section{Consent for publication}


Not applicable.

\section{Availability of data and materials}

Not applicable.

\section{Competing interests}

The authors declare that they have no competing interests.

\section{Funding}

This work was supported by JSPS KAKENHI (Grant Number 19K09438).

\section{Authors' contributions}

$\mathrm{YM}, \mathrm{CK}, \mathrm{SH}$, and $\mathrm{HI}$ contributed to the data acquisition, analysis, and interpretation. All authors contributed to data interpretation, critically revised the manuscript, and approved the final manuscript.

\section{Acknowledgements}

The authors would like to thank M. Yamada, who helped with data collection and sample collection. This work was supported by the Facility of the Laboratory Animal Science Research Support Center Institute for Research Promotion, Kagoshima University. We would like to thank Editage (www.editage.com) for English language editing.

\section{References}

1. Beale R, Reinhart K, Brunkhorst FM, Dobb G, Levy M, Martin G, et al. Promoting Global Research Excellence in Severe Sepsis (PROGRESS): lessons from an international sepsis registry. Infection. 2009;37:222-32.

2. Rudd KE, Johnson SC, Agesa KM, Shackelford KA, Tsoi D, Kievlan DR, et al. Global, regional, and national sepsis incidence and mortality, 1990-2017: analysis for the Global Burden of Disease Study. Lancet. 2020;395:200-11.

3. Rhodes A, Evans LE, Alhazzani W, Levy MM, Antonelli M, Ferrer R, et al. Surviving sepsis campaign: international guidelines for management of sepsis and septic shock: 2016. Intensive Care Med. 2017;43:304-77.

4. Ince C, Mayeux PR, Nguyen T, Gomez H, Kellum JA, Ospina-Tascón GA, et al. The endothelium sepsis. Shock. 2016;45:259-70.

5. Lupu F, Kinasewitz G, Dormer K. The role of endothelial shear stress on haemodynamics, inflammation, coagulation and glycocalyx during sepsis. J Cell Mol Med. 2020;24:12258-71.

6. Vásquez-Vivar J, Kalyanaraman B, Martásek P, Hogg N, Masters BS, Karoui H, et al. Superoxide generation by endothelial nitric oxide synthase: the influence of cofactors. Proc Natl Acad Sci USA. 
1998;95:9220-5.

7. Vásquez-Vivar J, Martásek P, Whitsett J, Joseph J, Kalyanaraman B. The ratio between tetrahydrobiopterin and oxidized tetrahydrobiopterin analogues controls superoxide release from endothelial nitric oxide synthase: an EPR spin trapping study. Biochem J. 2002;362:733-9.

8. Crabtree MJ, Smith CL, Lam G, Goligorsky MS, Gross SS. Ratio of 5,6,7,8-tetrahydrobiopterin to 7,8dihydrobiopterin in endothelial cells determines glucose-elicited changes in NO vs. superoxide production by eNOS. Am J Physiol Heart Circ Physiol. 2008;294:H1530-40.

9. Noguchi K, Hamadate N, Matsuzaki T, Sakanashi M, Nakasone J, Uchida T, et al. Increasing dihydrobiopterin causes dysfunction of endothelial nitric oxide synthase in rats in vivo. Am J Physiol Heart Circ Physiol. 2011;301:H721-9.

10. Kar S, Kavdia M. Modeling of biopterin-dependent pathways of eNOS for nitric oxide and superoxide production. Free Radic Biol Med. 2011;51:1411-27.

11. Rehm M, Bruegger D, Christ F, Conzen P, Thiel M, Jacob M, et al. Shedding of the endothelial glycocalyx in patients undergoing major vascular surgery with global and regional ischemia. Circulation. 2007;116:1896-906.

12. Carr AC, Rosengrave PC, Bayer S, Chambers S, Mehrtens J, Shaw GM. Hypovitaminosis C and vitamin $\mathrm{C}$ deficiency in critically ill patients despite recommended enteral and parenteral intakes. Crit Care. 2017;21:300.

13. Tyml K, Li F, Wilson JX. Septic impairment of capillary blood flow requires nicotinamide adenine dinucleotide phosphate oxidase but not nitric oxide synthase and is rapidly reversed by ascorbate through an endothelial nitric oxide synthase-dependent mechanism. Crit Care Med. 2008;36:235562.

14. Rittirsch D, Huber-Lang MS, Flierl MA, Ward PA. Immunodesign of experimental sepsis by cecal ligation and puncture. Nat Protoc. 2009;4:31-6.

15. Tani Y, Ohno T. Analysis of 6R- and 6S-tetrahydrobiopterin and other pterins by reversed-phase ionpair liquid-chromatography with fluorimetric detection by post-column sodium nitrite oxidation. $\mathrm{J}$ Chromatogr. 1993;617:249-55.

16. Wu F, Wilson JX, Tyml K. Ascorbate protects against impaired arteriolar constriction in sepsis by inhibiting inducible nitric oxide synthase expression. Free Radic Biol Med. 2004;37:1282-9.

17. Takeda M, Yamashita T, Shinohara M, Sasaki N, Takaya T, Nakajima K, et al. Plasma tetrahydrobiopterin/dihydrobiopterin ratio: a possible marker of endothelial dysfunction. Circ J. 2009;73:955-62.

18. Alkaitis MS, Crabtree MJ. Recoupling the cardiac nitric oxide synthases: tetrahydrobiopterin synthesis and recycling. Curr Heart Fail Rep. 2012;9:200-10.

19. Stuehr D, Pou S, Rosen GM. Oxygen reduction by nitric-oxide synthases. J Biol Chem. 2001;276:14533-6.

20. Mortensen A, Lykkesfeldt J. Does vitamin C enhance nitric oxide bioavailability in a tetrahydrobiopterin-dependent manner? In vitro, in vivo and clinical studies. Nitric Oxide. 2014;36:51- 
7.

21. de Grooth HJ, Manubulu-Choo WP, Zandvliet AS, Spoelstra-de Man AM, Girbes AR, Swart EL, et al. Vitamin $\mathrm{C}$ pharmacokinetics in critically ill patients: a randomized trial of four IV regimens. Chest. 2018;153:1368-77.

22. Tanaka H, Matsuda T, Miyagantani Y, Yukioka T, Matsuda H, Shimazaki S. Reduction of resuscitation fluid volumes in severely burned patients using ascorbic acid administration: a randomized, prospective study. Arch Surg. 2000;135:326-31.

23. Nakajima M, Kojiro M, Aso S, Matsui H, Fushimi K, Kaita Y, et al. Effect of high-dose vitamin C therapy on severe burn patients: a nationwide cohort study. Crit Care. 2019;23:407.

24. Wu F, Wilson JX, Tyml K. Ascorbate inhibits iNOS expression and preserves vasoconstrictor responsiveness in skeletal muscle of septic mice. Am J Physiol Regul Integr Comp Physiol. 2003;285:R50-6.

25. Mckinnon RL, Lidington D, Tyml K. Ascorbate inhibits reduced arteriolar conducted vasoconstriction in septic mouse cremaster muscle. Microcirculation. 2007;14:697-707.

26. Uchimido R, Schmidt EP, Shapiro NI. The glycocalyx: a novel diagnostic and therapeutic target in sepsis. Crit Care. 2019;23:16.

27. Ostrowski SR, Gaïni S, Pedersen C, Johansson PI. Sympathoadrenal activation and endothelial damage in patients with varying degrees of acute infectious disease: an observational study. J Crit Care. 2015;30:90-6.

28. Hatanaka K, Ito T, Madokoro Y, Kamikokuryo C, Niiyama S, Yamada S, et al. Circulating syndecan-1 as a predictor of persistent thrombocytopenia and lethal outcome: a population study of patients with suspected sepsis requiring intensive care(in press). Front Cardiovasc Med. 2021:1079.

29. Kawade N, Tokuda Y, Tsujino S, Aoyama H, Kobayashi M, Murai A, Horio F, et al. Dietary intake of ascorbic acid attenuates lipopolysaccharide-induced sepsis and septic inflammation in ODS rats. J Nutr Sci Vitaminol (Tokyo). 2018;64:404-11.

30. Lankadeva YR, Peiris RM, Okazaki N, Birchall IE, Trask-Marino A, Dornom A, et al. Reversal of the pathophysiological responses to gram-negative sepsis by megadose vitamin C. Crit Care Med. 2021;49:e179-90.

31. Kim J, Arnaout L, Remick D. Hydrocortisone, ascorbic acid, and thiamine (HAT) therapy decreases oxidative stress, improves cardiovascular function, and improves survival in murine sepsis. Shock. 2020;53:460-7.

32. Marik PE, Khangoora V, Rivera R, Hooper MH, Catravas J. Hydrocortisone, vitamin C, and thiamine for the treatment of severe sepsis and septic shock: a retrospective before-after study. Chest. 2017;151:1229-38.

33. Marik PE. Vitamin C for the treatment of sepsis: the scientific rationale. Pharmacol Ther. 2018;189:63-70.

34. Truwit JD, Hite RD, Morris PE, DeWilde C, Priday A, Fisher B, et al. Effect of vitamin C infusion on organ failure and biomarkers of inflammation and vascular injury in patients with sepsis and severe 
acute respiratory failure: the CITRIS-ALI randomized clinical trial. JAMA. 2019;322:1261-70.

35. Fujii T, Luethi N, Young PJ, Frei DR, Eastwood GM, French CJ, et al. Effect of vitamin C, hydrocortisone, and thiamine vs hydrocortisone alone on time alive and free of vasopressor support among patients with septic shock: the VITAMINS randomized clinical trial. JAMA. 2020;323:423-31.

36. Moskowitz A, Huang DT, Hou PC, Gong J, Doshi PB, Grossestreuer AV, et al. Effect of ascorbic acid, corticosteroids, and thiamine on organ injury in septic shock: the ACTS randomized clinical trial. JAMA. 2020;324:642-50.

37. Scholz SS, Borgstedt R, Ebeling N, Menzel LC, Jansen G, Rehberg S. Mortality in septic patients treated with vitamin C: a systematic meta-analysis. Crit Care. 2021;25:17.

38. Shin TG, Kim YJ, Ryoo SM, Hwang SY, Jo IJ, Chung SP, et al. Early vitamin C and thiamine administration to patients with septic shock in emergency departments: propensity score-based analysis of a before-and-after cohort study. J Clin Med. 2019;8:102.

39. Lv SJ, Zhang GH, Xia JM, Yu H, Zhao F. Early use of high-dose vitamin $\mathrm{C}$ is beneficial in treatment of sepsis. Ir J Med Sci. 2021;190:1183-8.

40. Patak P, Willenberg HS, Bornstein SR. Vitamin $C$ is an important cofactor for both adrenal cortex and adrenal medulla. Endocr Res. 2004;30:871-5.

41. Padayatty SJ, Doppman JL, Chang R, Wang Y, Gill J, Papanicolaou DA, et al. Human adrenal glands secrete vitamin $C$ in response to adrenocorticotrophic hormone. Am J Clin Nutr. 2007;86:145-9.

42. Cathcart IIIRF. Vitamin C: the nontoxic, nonrate-limited, antioxidant free radical scavenger. Med Hypotheses. 1985;18:61-77.

43. Moskowitz A, Andersen LW, Huang DT, Berg KM, Grossestreuer AV, Marik PE, et al. Ascorbic acid, corticosteroids, and thiamine in sepsis: a review of the biologic rationale and the present state of clinical evaluation. Crit Care. 2018;22:283.

\section{Figures}




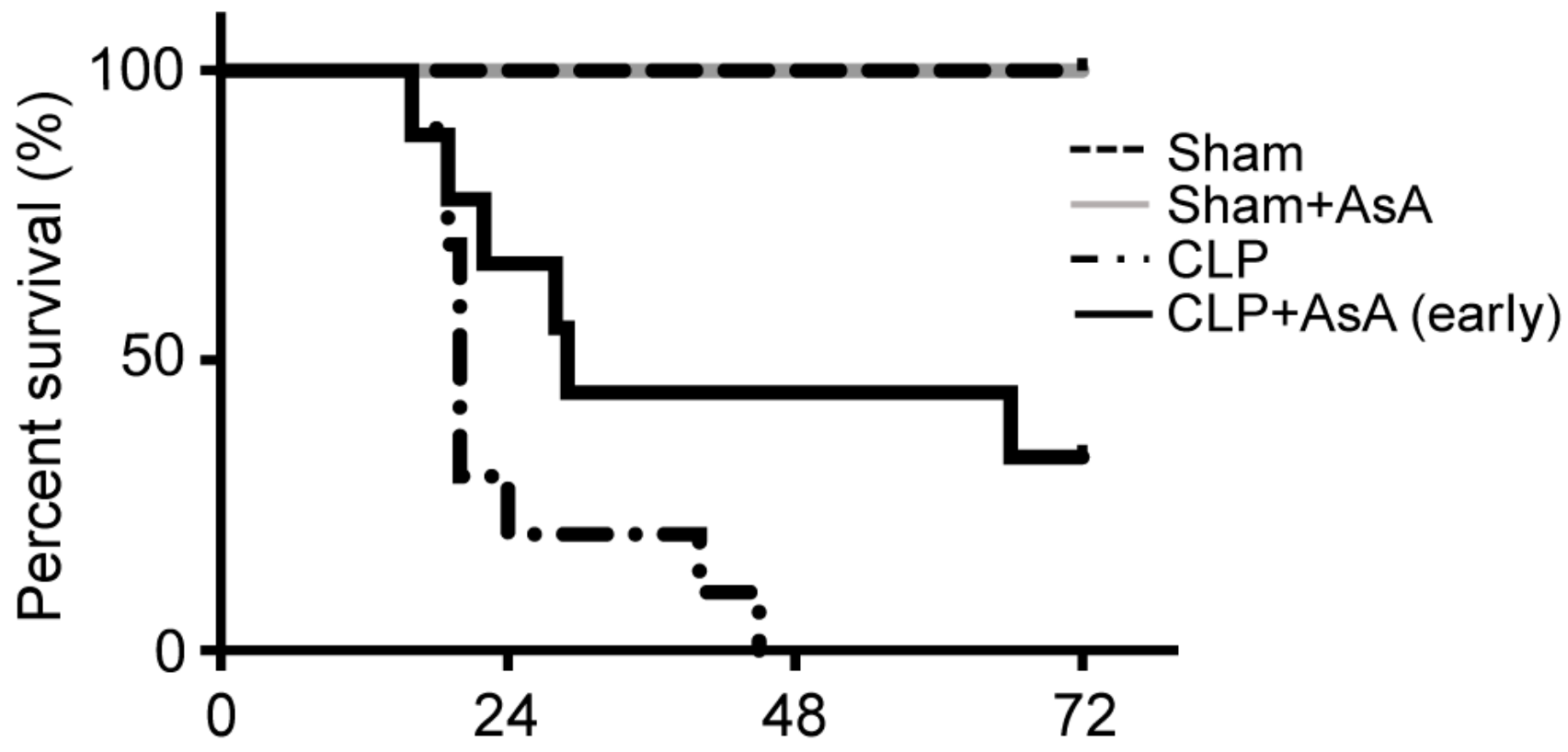

Hours

B

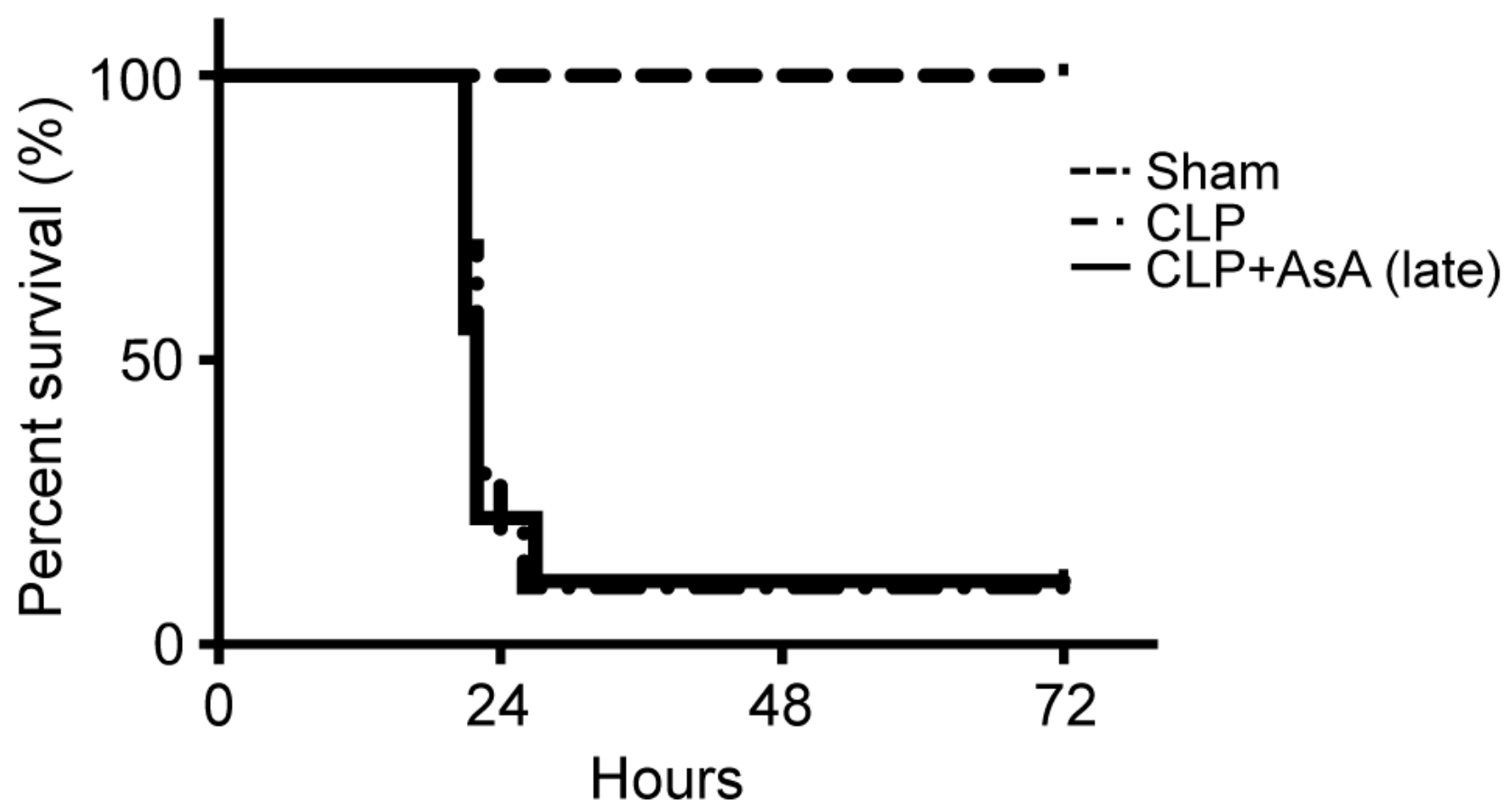

Figure 1

(A) Mice subjected to CLP, as described in the Methods section, for $72 \mathrm{~h}$ survival study. In the AsA administration group, AsA was injected subcutaneously immediately after the operation. The CLP + AsA (Early) mice group had a significantly prolonged survival rate compared to the CLP group. ${ }^{*} \mathrm{P}<0.05$ versus CLP. $\mathrm{n}=9$ or 10. (B) Mice subjected to CLP, as described in the Methods section, for $72 \mathrm{~h}$ survival study. AsA was injected subcutaneously $12 \mathrm{~h}$ after the operation. CLP + AsA (Early) mice showed no 
difference in the survival rate from the CLP group. ${ }^{*} \mathrm{P}<0.05$ versus CLP. Abbreviations: AsA, ascorbic acid; CLP, cecal ligation and puncture

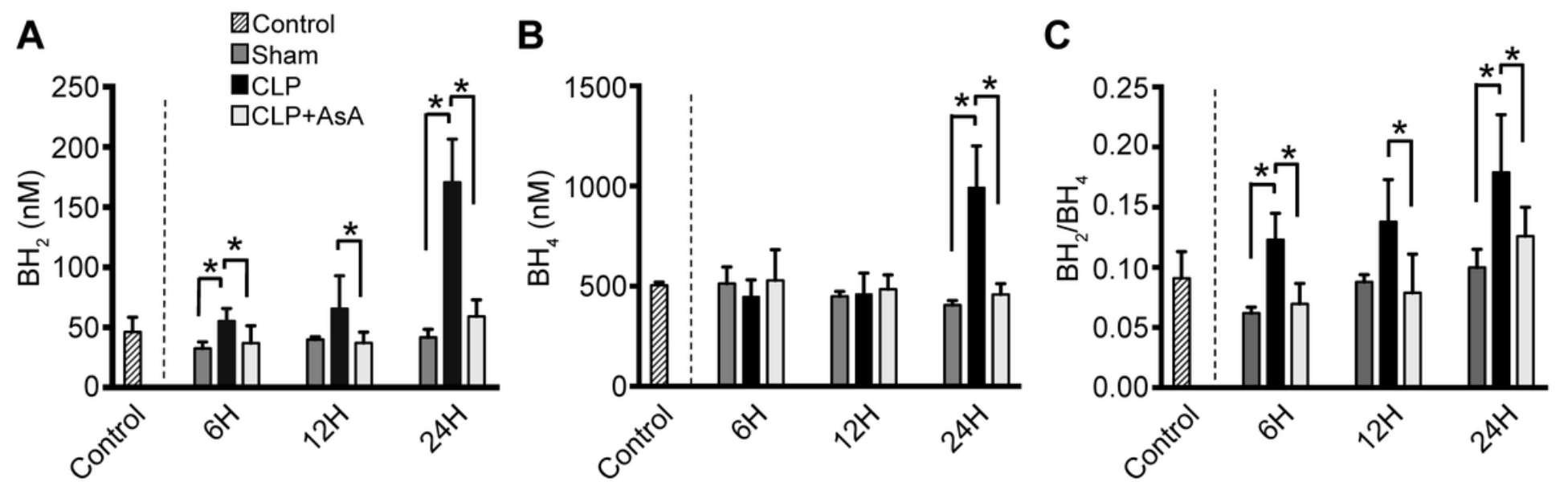

Figure 2

(A) $\mathrm{BH} 2$ concentration in the plasma was measured by HPLC. At 6 and $24 \mathrm{~h}$ after the operation, CLP group had significantly elevated $\mathrm{BH} 2$ concentration compared to CLP+ AsA (Early) and Sham groups. At $12 \mathrm{~h}$ after the operation, CLP group had significantly elevated $\mathrm{BH} 2$ concentration compared to $\mathrm{CLP}+\mathrm{AsA}$ (Early) group. $n=4-7$ per group, Error bars represent SE. ${ }^{*} \mathrm{P}<0.05$. (B) $\mathrm{BH} 4$ concentration in the plasma was measured by HPLC. At $24 \mathrm{~h}$ after the operation, CLP group had significantly elevated BH4 concentration compared to CLP+AsA (Early) and Sham groups. At 6 and $12 \mathrm{~h}$ after the operation, there was no significant differences between the groups. $n=4-7$ per group, Error bars represent $S E$. ${ }^{*}<<0.05$. (C) $\mathrm{BH} 2 / \mathrm{BH} 4$ ratio was calculated by dividing $\mathrm{BH} 2$ by $\mathrm{BH} 4$. At 6 and $24 \mathrm{~h}$ after the operation, CLP group had significantly elevated $\mathrm{BH} 2 / \mathrm{BH} 4$ ratio compared to $\mathrm{CLP}+\mathrm{AsA}$ (Early) and Sham groups. At $12 \mathrm{~h}$ after the operation, CLP group had significantly elevated $\mathrm{BH} 2 / \mathrm{BH} 4$ ratio compared to $\mathrm{CLP}+\mathrm{As} \mathrm{A}$ (Early) group. $\mathrm{n}=4-7$ per group, Error bars represent $S E .{ }^{*} \mathrm{P}<0.05$. Abbreviations: AsA, ascorbic acid; CLP, cecal ligation and puncture; $\mathrm{BH} 4$, tetrahydrobiopterin; $\mathrm{BH}$ 2, dihydrobiopterin; $\mathrm{SE}$, standard error; $\mathrm{HPLC}$, high-performance liquid chromatography 
A

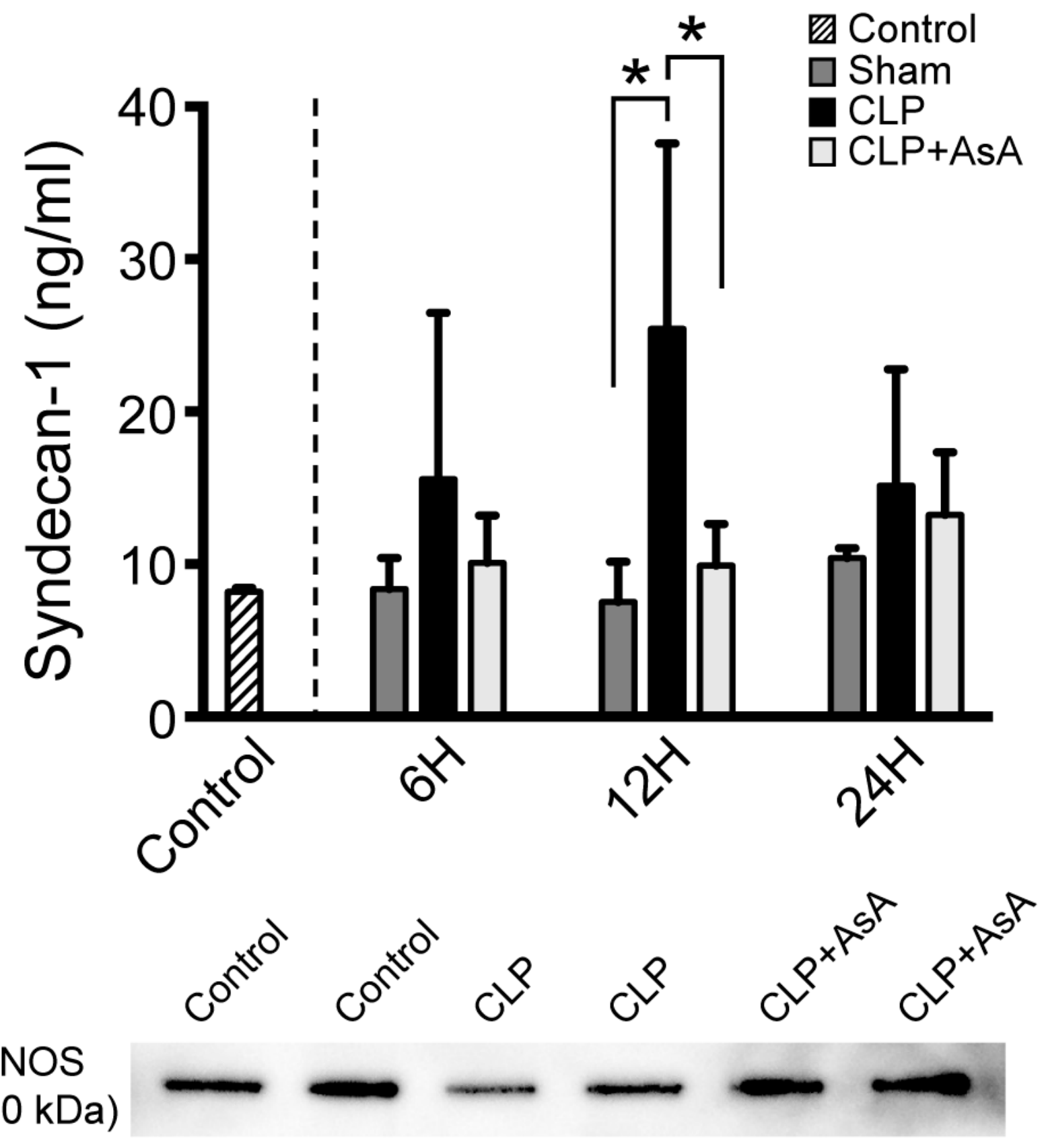

GAPDH (37 kDa)

Figure 3

(A) Plasma syndecan-1 was measured by ELISA kit. At $12 \mathrm{~h}$ after the operation, Syndecan-1 levels in the CLP group was significantly elevated compared to the CLP+AsA (Early) and Sham groups. $n=7-12$ per group, Error bars represent SE. ${ }^{*}<0.05$. (B) The expression of eNOS $(130 \mathrm{kDa})$ in the heart was measured by western blotting. All samples were taken $12 \mathrm{~h}$ after operation. The expression of eNOS was 
decreased in the CLP group, while the early AsA group maintained its expression. Abbreviations: AsA, ascorbic acid; CLP, cecal ligation and puncture; eNOS, endothelial NO synthase; SE, standard error

A

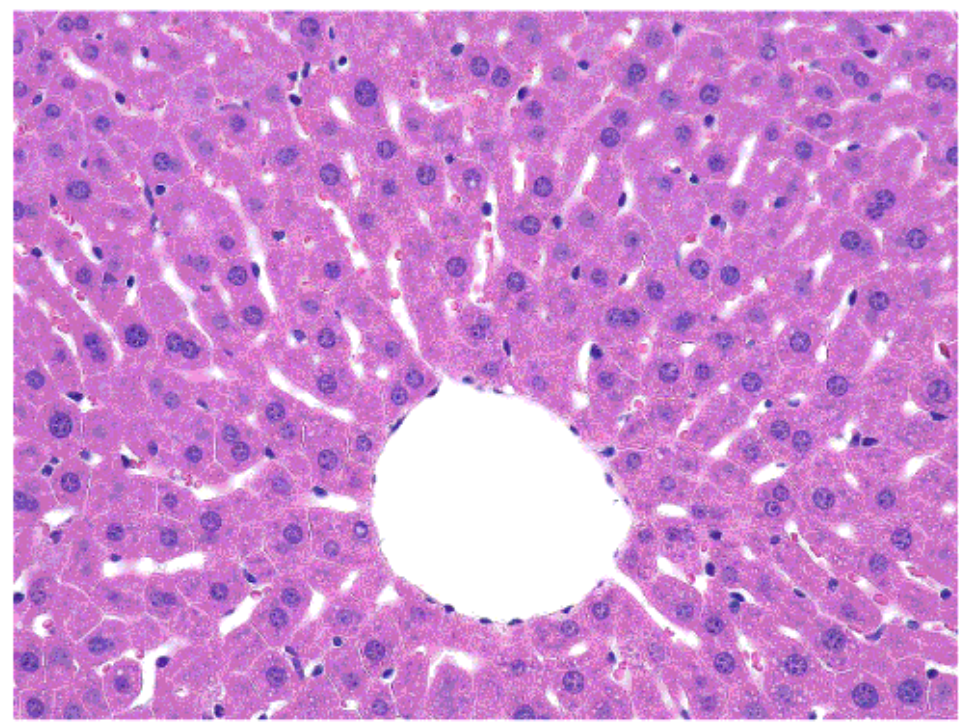

C

\section{CLP}

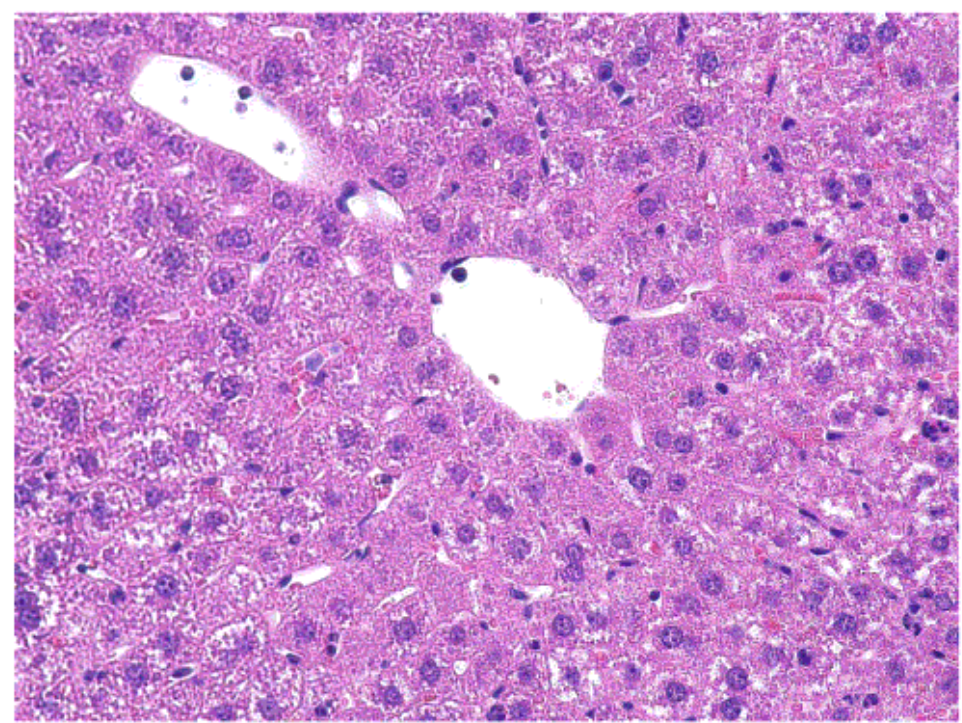

B

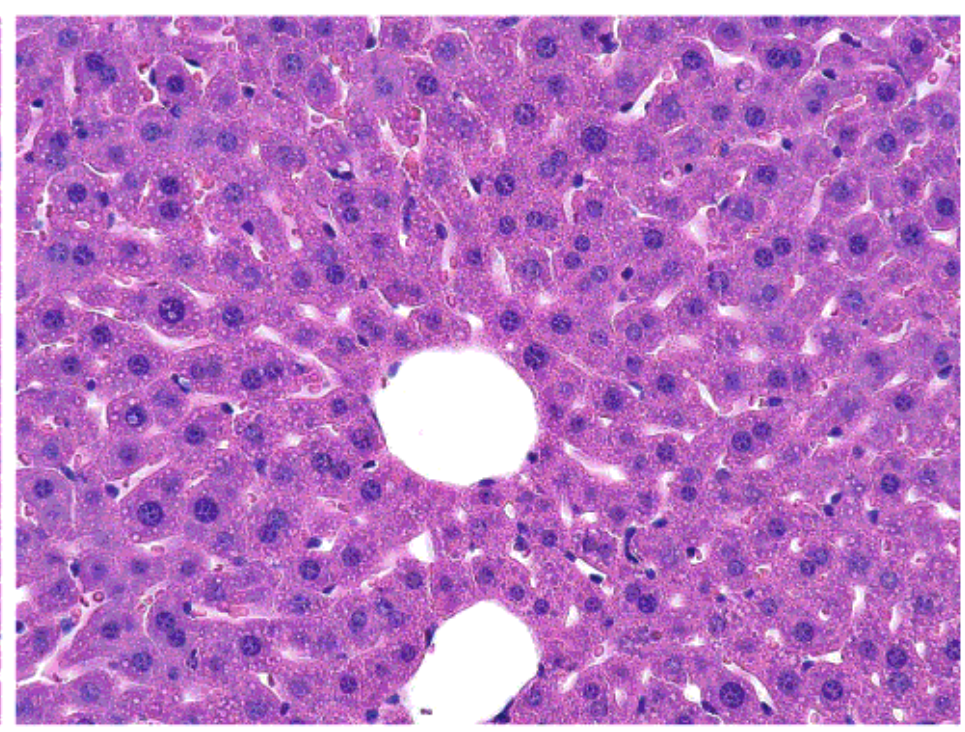

\section{D}

CLP+AsA

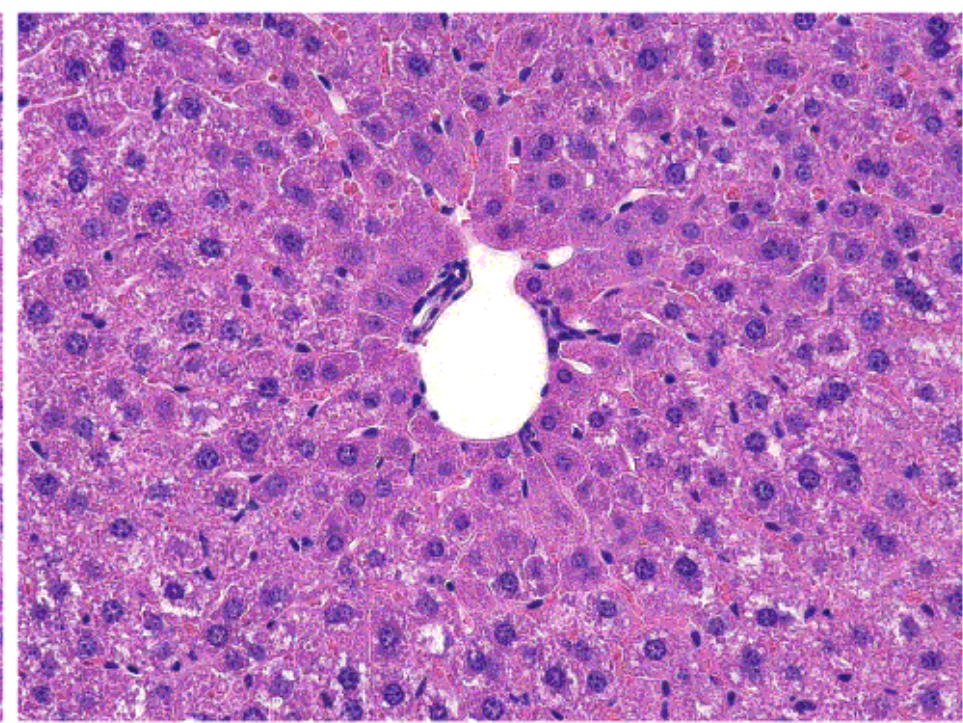

\section{Figure 4}

Histopathological examination of the liver of CLP-treated and untreated mice. A) B) Normal histology of liver tissues obtained from sham and control mice. C) Representative CLP induced liver damage. D) Representative liver of CLP mice treated with early AsA administration. Sham and CLP mice were killed $12 \mathrm{~h}$ after the operation. Original magnification, $\times 40$ Abbreviations: AsA, ascorbic acid; CLP, cecal ligation and puncture 